\title{
INTERPRETER'S NOTE
}

An amalgamation of more than four decades of research by Germany's leading pioneers in the field of law and economics, this cornerstone work echoes the frontiers of legal economic scholarship in the realm of civil law jurisdictions. The success of this book clearly resounds beyond German borders as it skilfully encapsulates all facets of the economic analysis of civil law in a rigorous but refined manner. In my view, a true asset in understanding and contextualising the underlying matter is the continued incorporation of empirical illustrations and current examples, paired with legal comparative angles to the discussion.

I would like to sincerely thank Hans-Bernd Schäfer and Claus Ott for entrusting me with the challenging yet thrilling task of translating, interpreting and contributing to this monumental scholarly work.

Axel Moeller

Oxford, April 2021 